\title{
Espaço público e parques urbanos: a disputa pública pelo novo Parque Augusta
}

\section{Public space and urban parks: the public dispute for the new Parque Augusta}

\section{Espacio público y parques urbanos: la disputa pública por el nuevo Parque Augusta}

Henrique Politi Corsi, Mestrando do Programa de Pós-Graduação Stricto Sensu em Arquitetura e Urbanismo, Universidade Presbiteriana Mackenzie.

E-mail: corsi.henrique@gmail.com (DDORID: https://orcid.org/0000-0003-1762-9721

Eunice Helena Sguizzardi Abascal, Doutora em Arquitetura e Urbanismo, Docente no Programa de Pós-Graduação Stricto Sensu em Arquitetura e Urbanismo, Universidade Presbiteriana Mackenzie.

E-mail:eunicehab@gmail.com DORCID: https://orcid.org/0000-0002-7721-220X

Para citar este artigo: ABASCAL, E. H. S.; CORSI, H. P. Espaço público e parques urbanos: a disputa pública pelo novo Parque Augusta. Cadernos de Pós-Graduação em Arquitetura e Urbanismo, São Paulo, v. 22, n.1, p. 119-135, 2022. DOI 10.5935/cadernospos.v22n1p119-135

Submissão: 2021-03-28

Aceite: 2021-09-20

\section{Resumo}

O presente artigo utiliza o caso recente do Parque Augusta para iluminar a importância da participação da sociedade na reivindicação de novos espaços públicos na cidade de São Paulo, em especial, no tocante aos parques urbanos. Destacando o conceito de direito à 
cidade e a dimensão humana no planejamento urbano, ressalta-se a existência de forças conflituosas na produção do espaço público e levanta-se a questão: para que e para quem são feitos esses locais? O trabalho conclui que a implementação de novos parques urbanos é essencial para concretizar a ideia de que a cidade e suas instâncias comunitárias devem ser planejadas para a ocupação das pessoas, entendendo que a pressão da sociedade civil é fundamental nesta lógica.

Palavras-chave: Espaço público; Sociedade civil; Parques urbanos; Parque Augusta.

\section{Abstract}

The present article uses the recent case of Parque Augusta to highlight the importance of society's participation in claiming new public spaces in the city of São Paulo, especially regarding Urban Parks. Stressing the concept of the right to the city and the human dimension in urban planning, the existence of opposing forces in the production of public space is highlighted and the question arises: for what and for whom are public spaces made? The work concludes that the implementation of new urban parks are essential to materialize the idea that the city and public spaces must be planned for the occupation of people and that pressure from civil society is fundamental in this logic.

Keywords: Public space; Civil society; Urban parks; Parque Augusta.

\section{Resumen}

En este artículo se utiliza el reciente caso del Parque Augusta para poner de relieve la importancia de la participación de la sociedad en la demanda de nuevos espacios públicos en la ciudad de São Paulo, especialmente en lo que respecta a los parques urbanos. Destacando el concepto de derecho a la ciudad y la dimensión humana en la planificación urbana, pone de relieve la existencia de fuerzas opuestas en la producción del espacio público y plantea la pregunta: ¿para qué y para quién se hacen los espacios públicos? El trabajo concluye que la implementación de nuevos parques urbanos es esencial para hacer realidad la idea de que la ciudad y los espacios públicos deben planificarse para la ocupación de personas y que la presión de la sociedad civil es fundamental en esta lógica.

Palabras clave: Espacio público; Sociedade civil; Parques urbanos; Parque Augusta. 


\section{INTRODUÇÃO}

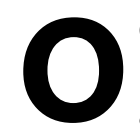

espaço público contemporâneo é um direito de todos os cidadãos. Esse é o ponto de partida desta investigação, com a qual pretende-se contribuir para a elucidação da importância, para a cidade e para as pessoas, da ocupação de espaços públicos, particularmente parques urbanos, analisando, para esse fim, a disputa pelo novo Parque Augusta.

O direito à cidade (LEFEBVRE, 2016) fundamenta o planejamento urbano enquanto fator determinante para que espaços públicos se tornem acessíveis e convidativos a apropriação, sem discriminação e imposição de barreiras, sejam elas geográficas, econômicas ou políticas.

Um planejamento urbano influenciado por fatores, como, o mercado imobiliário ou a predileção por automóveis particulares, pode afastar e dificultar a participação popular nas áreas urbanas. Em contrapartida, nos casos em que a dimensão humana foi preservada, notamos um maior uso e uma transformação do espaço urbano. Neste diapasão, insere-se o outro conceito deste trabalho: parque urbano, entendido como espaço de livre acesso gratuito e, portanto, universal.

Assim sendo, esta comunicação está estruturada em torno destes dois conceitos: espaço urbano e parque urbano. Como exemplo da importância dos espaços públicos, em particular os parques, a disputa pelo terreno hoje conhecido como Parque Augusta, localizado na região central da cidade de São Paulo, servirá como estudo de caso. Em um primeiro momento, explora-se a necessidade e a relevância de se construir ou reconstruir cidades. Na sequência, denota-se o conceito e o surgimento dos parques urbanos, e como as suas características intrínsecas podem auxiliar na conexão entre cidade e cidadão. Por fim, no caso do Parque Augusta, discute-se a luta dos cidadãos no intuito de reivindicar um espaço verde e público no centro da maior cidade da América Latina.

\section{Espaço público para todos?}

Nos últimos dois séculos, as cidades têm sido o destino de intenso êxodo, aumentando sua concentração populacional, gerando-se uma demanda por políticas públicas que visem à melhoria da qualidade de vida de seus habitantes. De acordo com a Organização das Nações Unidas (ONU), em seu relatório de 2019 - FAO Framework for the Urban Food Agenda - Leveraging Sub-National and Local Government Action to Ensure Sustainable Food Systems and Improved Nutrition - naquele ano, 55\% da população mundial vivia em centros urbanos. Ainda de acordo com esse relatório, espera-se que esse número aumente nos próximos anos, chegando a $66 \%$ em 2050, um acréscimo real de 2,5 bilhões de pessoas.

Diante dessa realidade, as cidades terão que ser remodeladas, e a dimensão humana deve constar no centro dessa mudança. Segundo Gehl (2015), o planejamento urbano por décadas mitigou a dimensão humana, enquanto outros atores e prioridades ganharam maior força. Ainda de acordo com o autor, o recente modelo não deu 
prioridade ao espaço público e às áreas pedonais, e não compreendeu a importância dos espaços coletivos como local de encontro entre os citadinos. Esforços foram direcionados para um outro caminho, no qual predominou a melhor acomodação do tráfego de veículos e o crescimento do número de construções, dificultando o acesso aos espaços de uso coletivo.

Gehl (2015) também pontua que cidadãos que utilizam espaços urbanos deparam-se com dificuldades ao usufruir deles. Falta de espaço, ruído, poluição e risco de acidente são alguns dos obstáculos que a maioria das cidades impõe àqueles que tentam desfrutar das suas áreas comuns. Para tornar o espaço público mais convidativo à participação popular, faz-se necessário uma mudança no planejamento urbano e nas formas de regulação.

Importante também destacar que o direito à cidade, segundo Lefebvre (2016), é a forma superior dos direitos, englobando o direito à liberdade, à individualização das formas de sociabilidade, ao habitat e ao habitar. $\mathrm{O}$ autor prossegue e diz que o direito à obra (à atividade participante) e o direito à apropriação (termo distinto do direito à propriedade) também englobam-se no direito à cidade.

Consoante, Burgos (2016) reforça a ideia de que o direito à cidade é o conjunto de direitos materiais e imateriais, que devem ser usufruídos por todos os cidadãos, sem qualquer distinção. A autora ressalta que é necessário reivindicar o uso e a apropriação do espaço público, mesmo que a predominância de forças contrárias, principalmente mercadológicas, esfacelam a sociabilidade, esvaziam os sentidos originários e próprios dos espaços públicos, e enfatizam a lógica do espaço privado.

De acordo com Mitchell (1995), o espaço público nas cidades modernas sempre foi um híbrido do uso social e do consumo. Entretanto, no século XXI, o mercado tem se sobressaído, e o papel do espaço público, como meio para o exercício democrático, tem sucumbido ao poder econômico. Esse autor aponta que a pretexto do conforto, segurança e lucro, a participação democrática se vê mitigada por intervenções urbanas sob medida, priorizando relações de consumo. As relações de troca estão na base da competição dos lugares (ROLNIK, 2019), e a concorrência supera o mutualismo, seguindo um pensamento mercadológico. Ante o exposto, ressalta-se a importância do espaço público para que a cidade volte a exercer o seu papel fundamental de acolhimento e ocupação primordial por seus cidadãos.

Deste modo, apresenta-se com relevância a apropriação do espaço público, de maneira a reverter esse cenário de privatização, o qual, conforme Burgos (2016), tem várias causas. Trata-se de tema interdisciplinar e complexo, abrangendo desde a função social da propriedade, direito à mobilidade, infraestrutura básica, participação ativa da população nas decisões e compreensão da cidade enquanto organismo vivo, até o direito de se desfrutar do ócio e disseminar cultura.

No Brasil, possuímos importantes ferramentas jurídicas, como a Constituição Federal de 1988 e o Estatuto da Cidade, chancelado em 2001, para incentivar a participação popular junto aos espaços urbanos (ABASCAL; BILBAO, 2020). No ordenamento jurídico do Estatuto da Cidade, prevê-se a participação da sociedade civil de forma não apenas opinativa, mas também participativa, na formulação, execução e acompanhamento das políticas públicas de desenvolvimento urbano. 


\section{Parques urbanos - o alívio do campo na cidade}

O direito ao uso dos Parques Urbanos deve ser estendido a todos os habitantes urbanos. Dalben (2016) corrobora com esse entendimento e assim como os cidadãos têm o direito coletivo à cidade, este direito deve ser estendido ao uso das áreas de maior proximidade com a natureza nas cidades. $\mathrm{O}$ autor pontua que essa reivindicação perpassa temas como ecologia, meio ambiente e a própria necessidade de prover espaços verdes de convivência coletiva e vida pública.

Os parques urbanos têm seu espaço, no entanto, muitas vezes segregador (HENRIQUE, 2009), e usufruídos por público seleto, realizando prioritariamente formas de consumo (HARVEY, 2014), estando entre estas, o consumo residencial em suas proximidades, voltado a segmentos de maior renda. Muitos parques estão localizados em áreas valorizadas, nas quais o mercado imobiliário atua para os padrões mais favorecidos da sociedade, limitando o usufruto destes espaços públicos àqueles com maior poder aquisitivo. A satisfação pessoal se sobrepõe a um projeto coletivo, deixando espaços verdes da cidade à mercê da especulação imobiliária. Consequentemente, como parte da lógica de valorização da terra urbana, esse cenário mitiga o acesso aos parques, em maioria, localizados praticamente fora do alcance dos menos favorecidos, mesmo que façam parte da cidade, do tecido e do espaço construídos.

Casimiro (2018) mostra que o parque público é uma tipologia de espaço verde que surge a partir do século XIX, por meio de transformações progressivas de espaços anteriormente ajardinados, e que ganharam uma dimensão citadina. O autor (2018) distingue essas duas categorias de espaços, comparando-as também com as praças e os largos.

O teórico também ensina que, na Europa Medieval, praças e largos urbanos detinham uma estrutura morfológica reconhecida em meio às áreas urbanas, como na Praça de São Marcos e Praça de São Pedro. Entretanto, notava-se a ausência, nesses locais, de bens naturais em sua composição. Naquela época, os elementos caractísticos da natureza estavam reduzidos aos ambientes extra-muros, na porção rural, e eram vistos como elementos estranhos à dinâmica de produção urbana. Em contrapartida, os jardins eram reconhecidos como locais privilegiados e, por vezes, fechados, usufruídos para fins de repouso, conforto e contemplação. Os jardins ainda resguardavam uma porção de natureza e carregavam o arquétipo do paraíso (SALDANHA, 2005).

As diferenças entre praça e jardim não se esgotam em sua origem, tendo reflexos também na destinação dos espaços.

\footnotetext{
As praças e largos eram espaços de convergência de vias públicas que subsidiavam uma dinâmica de reunião para os mais diversos usos: comércio, festas populares, discursos políticos ou simples ocupação citadina. Era o local não natural, aberto à vida pública, em que prevalecia a informalidade e a livre apropriação. O jardim, por sua vez, era o espaço vegetado da admiração, da formalidade e do isolamento, estando comumente situado em zonas rurais (CASIMIRO, 2018, p.58).
}

Os jardins, em um momento de adaptação às novas necessidades para um público maior, ganharam mais espaço, de modo a fundar uma nova tipologia de espaço livre urbano: os parques. Para Casimiro (2018), essas áreas verdes recentes, complementares 
do ambiente da cidade, apresentam duas características inéditas que as distinguem dos jardins, praças e largos: os parques realizam uma avizinhação com elementos da natureza e ideias campestres junto ao cenário urbano, e desempenham, ao mesmo tempo, uma importante função social e cultural. Isso dá por viabilizarem desde a contemplação do próprio local até realização de atividades físicas, de lazer ou de reprodução de hábitos culturais.

Dessa forma, os parques urbanos podem ser assim definidos:

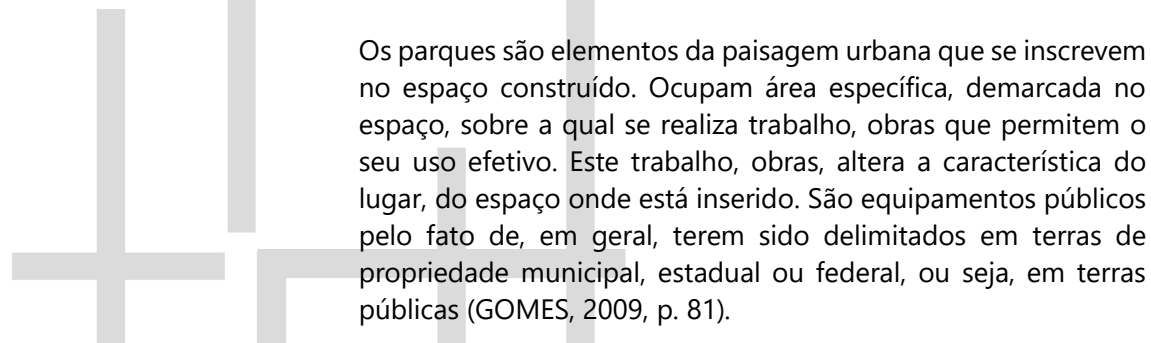

Ainda conforme Gomes (2009), os parques urbanos são espaços que, apesar de redimensionados e ressignificados constantemente, remetem a valores históricos, ao coletivismo, ao lazer, à natureza e ao poder. Nas sociedades modernas, os parques urbanos humanizaram a cidade industrial e a nova realidade urbana que emergiu neste período. Gomes (id.) mostra que, enquanto a cidade, no imaginário popular, era símbolo de conhecimento, luz e modernidade, o campo remetia às trevas, à ignorância e ao atraso. A cidade representava a civilidade, o lugar de novas ideias e encontros, sem ignorar os males a ela associados, como a ambição, a mundanidade, o caos, a monotonia e a poluição.

Os parques urbanos surgiram como resposta às mazelas decorrentes da industrialização (GOMES, 2009), e do modo de vida dos trabalhadores nas fábricas, ao permanecer grande parte da jornada diária reclusos. Com o objetivo de amenizar os desprazeres urbanos e as precárias condições humanas comuns nas cidades industriais, essas novas áreas verdes propuseram um afastamento do caos e um refúgio, sem se afastar do ambiente citadino. Esse refúgio de paz, contraditoriamente, fazia alusão ao campo, ao rural e à natureza.

Aos poucos, reconheceu-se o valor desses espaços verdes em meio ao mundo concreto das cidades. Gomes (2009) ressalta que, enquanto insistia em destruir a natureza e se distanciar do trabalho do campo, a cidade industrial, estimulava projetos de cidade que detinham o enaltecimento da natureza como um de seus pilares. Esse pensamento ambiental está conectado a uma tentativa de aprimorar a qualidade de vida urbana. Surgiu, nesse momento, a percepção coletiva de queo desenvolvimento urbano moderno necessitava ser sustentável, convergente à expansão de espaços verdes nas cidades.

Como vimos, a demanda por qualidade de vida na contemporaneidade impulsionou a criação de novos parques urbanos. Sakata (2018) reforça que o parque urbano é, para aqueles que buscar emular a vivência da paisagem campestre, uma forma de refúgio no ambiente urbano, tornando-se, consequentemente, um cenário idealizado, o qual pressupõe que seja possível alcançar um isolamento do meio citadino. A autora aponta uma possível diferenciação que pode ser percebida pelos que frequentam parques localizados dentro das cidades, conforme exposto abaixo: 


\begin{tabular}{|c|c|}
\hline $\begin{array}{c}\text { Atributos associados aos espaços } \\
\text { urbanos }\end{array}$ & $\begin{array}{c}\text { Atributos associados aos espaços dos } \\
\text { parques }\end{array}$ \\
\hline Construído & Livre \\
\hline Coberto & Aberto \\
\hline Apertado & Amplo \\
\hline Seco & Vegetado \\
\hline Sensação de ar poluído & Sensação de ar mais limpo \\
\hline Pessoas com pressa & Pessoas passando o tempo \\
\hline Pessoas preocupadas & Pessoas relaxadas \\
\hline Com automóveis & Sem carros \\
\hline Crianças contidas & Crianças Ativas \\
\hline
\end{tabular}

Quadro 1: Oposiões associadas a espaços urbanos e parques. Fonte: Elaborado pelos autores, com base nos dados de Sakata (2018, p. 44).

\section{Parque Augusta - história e disputa pelo espaço público}

A área que hoje conhecemos como Parque Augusta, objeto de análise deste artigo, localiza-se na região central da cidade de São Paulo, especificamente na Rua Augusta, entre as vias paralelas Rua Marquês de Paranaguá e Rua Caio Prado. De acordo com Júnior e Guimarães (2015), o terreno ocupa aproximadamente metade de um quarteirão e tem $23.733 \mathrm{~m}^{2}$ de área.

Essa expressiva porção do espaço é ocupada por um bosque de vegetação original remanescente da Mata Atlântica, com aproximadamente 800 árvores; atualmente é tombada por meio da Resolução 24/2004 do Conselho Municipal de Preservação do Patrimônio Histórico, Cultural e Ambiental da Cidade de São Paulo (CONPRESP). Diversas foram as transformações ocorridas no local, especialmente durante o século $X X$, resultando em mudanças estruturais de sua função. Faz-se, aqui, um recorte temporal a partir do começo do século passado para resgatar a história do local.

De acordo com Corrêa (2014), a princípio, a área pertencia à família Uchôa, e nesse local, no ano de 1902, foi construído um palacete residencial projetado por Victor Dubugras. Veiga (2015) explica que em 1906 o conjunto foi vendido para as religiosas da ordem de Nossa Senhora das Cônegas de Santo Agostinho. No ano seguinte, inaugurou-se o Colégio Des Oiseaux em uma edificação específica para esse fim.

Segundo Hori (2018), o bosque existente $\bar{\tau}_{\bar{\tau}}$ criado pela família Uchôa foi mantido e ampliado pelas freiras. Além disso, já desde o início do século $X X$, foi incluída na escritura do terreno uma cláusula pétrea para que o público tivesse acesso ao bosque, e que mencionava a obrigatoriedade de todo e qualquer proprietário de manter o espaço aberto por meio de uma passagem permanente entre as Ruas Caio Prado e Marquês de Paranaguá. O tradicional colégio feminino, que teve em seu quadro alunas como Ruth Cardoso e Marta Suplicy, foi mantido pelas religiosas até 1969, quando suas atividades foram encerradas. 
Em 1970, por sua vez, foi realizado o primeiro Decreto de Utilidade Pública (DUP) visando a demolição do prédio e construção de um jardim público. No entanto, em 1973, os proprietários reverteram o DUP e anunciaram a edificação de um hotel com 1.400 apartamentos, na época avaliado em US\$ 40 milhões, o que implicaria a derrubada de apenas cinco árvores do local (CORRÊA, 2014). No ano posterior ao projeto, o edifício do colégio foi demolido.

Todavia, ainda conforme Corrêa (2014), esse plano não foi efetivado; em 1977, a área foi adquirida pela Construtora Teijin, que pretendeu erigir o maior complexo hoteleiro da América Latina. O autor ainda nos conta que, em 1996, Armando Conde, ex-banqueiro do Banco de Crédito Nacional (BCN), comprou o terreno da Construtora Teijin.

Não obstante figurar como propriedade privada, como mencionado, a área do bosque sempre esteve destinada ao interesse público por conta da cláusula pétrea há muito consolidada escritura. E, de fato, como explica Hori (2018), o Parque Augusta foi reconhecido, em 2002, pelo poder público no Plano Diretor Estratégico (PDE) da Cidade de São Paulo, que previa a sua construção até 2014.

Reforçando a relevância pública do parque, em 2004, ocorreu o tombamento da área por meio da supracitada Resolução 24/2004 do CONPRESP, a qual contemplava a preservação do bosque original e das árvores isoladas, da casa do bosque, do edifício remanescente da escola religiosa, e do portal principal, à Rua Caio Prado.

No ano de 2006, o proprietário do terreno anunciou que iria construir um hipermercado no local. Em resposta, foi criado o grupo Aliados do Parque Augusta, primeiro movimento pelo qual a sociedade civil organizada passou a reivindicar a utilização da área como um espaço público, para, por fim, idealizar o Parque Augusta (HORI, 2018).

Foi organizado, então, um abaixo-assinado, que contou com aproximadamente 15 mil assinaturas a favor do parque e, com o apoio de vereadores, o Aliados do Parque Augusta elaborou e apresentou um projeto de lei para a criação do mesmo. Em 2008, o então prefeito da cidade de São Paulo, Gilberto Kassab, declarou o espaço como sendo de utilidade pública e, como Veiga (2015) expõe, em 2011, foi autorizada a criação do Parque Augusta pela Câmara Municipal de São Paulo.

Ainda no ano de 2012, as empresas Cyrela e Setin, deram um primeiro e significante passo para a aquisição do terreno apresentando o seu projeto, que originalmente contemplava a construção de duas torres (CORRÊA,2014). Segundo nos esclarece Corrêa (2014), no dia 23 de dezembro de 2013 o então prefeito da cidade de São Paulo, Fernando Haddad, sancionou a Lei Ordinária Municipal n 15.941/13, que autorizava a criação do Parque Augusta.

Após a aprovação da Lei, os proprietários do terreno decidiram fechar os portões de acesso ao parque, proibindo, assim, a população de visitar o bosque, algo inédito até então. Com isso, desrespeitou-se "pela primeira vez, em quase 80 anos, a obrigatoriedade da fruição pública prevista em escritura, impedindo a população de usufruir do Parque Augusta, apropriado pelos moradores desde a década de 1970" (HORI, 2018, p. 179). 
Diante desse novo cenário, a sociedade civil, irresignada, reorganizou-se e agiu de forma mais enérgica junto ao poder público, buscando viabilizar o parque em detrimento da iniciativa das incorporadoras. A sociedade civil teve parte de sua demanda atendida pela administração pública.

Como explica Hori:

\begin{abstract}
A pressão popular possibilitou que o Parque Augusta fosse reconhecido (de novo) no PDE de 2014 e permitiu que a área do parque fosse enquadrada como uma ZEPAM. O novo zoneamento, porém, não impediu as construtoras de continuarem insistindo no projeto, já que podiam considerar o zoneamento antigo para a construção do empreendimento por meio do direito de protocolo, instrumento anacrônico que coloca o interesse do proprietário acima de políticas urbanas orientadas pelos princípios da função social da propriedade e da gestão democrática das cidades $(2018$, p. 181).
\end{abstract}

Entre 2015 e 2018, observou-se, então, um acirramento do conflito que já há alguns anos se delineava, o que culminou na judicialização da disputa. Em 2014, grupos organizados da sociedade civil ingressaram com uma ação civil pública com pedido liminar junto à Justiça Estadual paulista, pela qual demandavam a abertura imediata dos portões, alegando a ilegalidade das medidas tomadas pelas incorporadoras (HORI, 2018).

Em janeiro de 2015, quase um ano após a proposta da ação, mas sem a concessão da abertura dos portões, grupos ativistas em favor do Parque Augusta ocuparam o terreno. A ação destes conseguiu desobstruir uma das entradas e tomaram o espaço durante dois meses como forma de protesto, dando visibilidade às suas reivindicações, especialmente à exigência de cumprimento da Lei 15.941/13 (HORI, 2018), a qual autorizava a criação do parque. Enquanto durou a ocupação, os militantes promoveram shows, intervenções artísticas e debates no local.

Em março daquele ano, uma ordem judicial determinou a reintegração de posse do terreno, cumprida pela Polícia Militar do Estado de São Paulo no dia 4 de março de 2015 (MELLO, 2015). Ainda naquele mês, devido a pressões de grupos organizados da sociedade civil, o Ministério Público do Estado de São Paulo propôs uma nova ação civil pública contra a Cyrela e a Setin, na qual pediu a declaração da perda do lote do bosque pelas infrações cometidas quanto a manutenção do patrimônio tombado e o pagamento de danos morais coletivos no valor de $\mathrm{R} \$ 500.000,00$ diários pelo fechamento dos portões do parque (HORI, 2018). Sem embargo, decretou-se, em abril de 2015, a reabertura do terreno, prevendo-a para julho daquele ano.

Ainda em 2015, como mostram Abascal e Bilbao (2015), elaborou-se um projeto de requalificação que deveria ser realizado pela iniciativa privada em conjunto com a Prefeitura. Nesse projeto, as construtoras poderiam erguer três torres, com até 45 metros de altura, não ocupando mais do que 33\% da área do terreno, permitindo que o espaço restante fosse utilizado para a implementação do parque. Os autores ressaltam que no mesmo ano, devido à pressão popular, o CONPRESP determinou que 700 árvores nativas da mata atlântica teriam que ser preservadas. 
Em meio às disputas judiciais pelo espaço, um acordo começou a ser efetivamente desenhado em 2015, quando o MPE-SP firmou um compromisso com a Prefeitura, intentanto adquirir o terreno, destinando verba que seria recuperada aos cofres públicos para esse fim. (MACHADO, 2016). De acordo com Machado (2016), em agosto de 2016, o MPE-SP recuperou US\$ 25 milhões para os cofres da prefeitura, montante pago pelos bancos UBS e Citibank em razão de uma ação judicial relativa a movimentações financeiras suspeitas ocorridas na gestão do ex-prefeito Paulo Maluf.

O acordo entre o Ministério Público e a gestão municipal previu a utilização de $R \$ 40$ milhões desse montante para a aquisição do terreno do parque. Nesta conjuntura e junto às construtoras, a Prefeitura propôs, além do valor para a aquisição do terreno, o encerramento de qualquer processo judicial movido contra as empresas (MACHADO, 2016). A proposta foi recusada sob a justificativa de que o montante apresentado seria muito inferior ao preço real da cotação do terreno no mercado imobiliário.

Como solução para o impasse, o Ministério Público apresentou a troca de espaços ociosos e sem restrições ambientais pela área do Parque Augusta como contraproposta. Diante do novo quadro, o novo prefeito de São Paulo, empossado em 2017, João Dória apoiou a ideia e reabriu as negociações com as construtoras (MACHADO; SANTIAGO, 2017). Assim, em julho de 2017, o município de São Paulo anunciou a permuta de um terreno de $18 \mathrm{mil} \mathrm{m}^{2}$ da Prefeitura Regional de Pinheiros pela área do parque (HORI, 2018).

Adicionalmente, as construtoras ainda deveriam arcar com outras contrapartidas:

[...] foram anunciadas a reforma da Praça Victor Civita, localizada ao lado do terreno de Pinheiros a ser permutado, e da Praça Roosevelt, próximo ao Parque Augusta, e sua manutenção por um prazo de dois anos. Além disso, foi previsto a construção de uma nova sede para a Prefeitura Regional de Pinheiros e para a Companhia de Engenharia de Tráfego (CET), hoje situada no terreno de Pinheiros, além de uma creche e um centro para atendimento de dependentes químicos (HORI, 2018, p. 189).

Essa permuta gerou muita controvérsia; a sociedade civil, por exemplo, criticou a forma como a negociação foi feita e os valores envolvidos. De acordo com a perícia da Prefeitura, o valor do terreno do Parque Augusta foi estimado em R\$137 milhões de reais, enquanto a área a ser permutada em Pinheiros foi avaliada em $R \$ 186$ milhões, uma diferença de R\$ 49 milhões. Essa diferença seria usada para arcar com os custos das contrapartidas citadas anteriormente. Já a perícia das construtoras indicou um valor de R\$139 milhões para o Parque Augusta e R\$141,5 milhões para a área de Pinheiros, uma diferença de apenas $\mathrm{R} \$ 2,5$ milhões de reais, o que, de acordo com as incorporadoras, não justificava as imposições às demais compensações impostas (HORI, 2018). No entanto, esse acordo também não foi concretizado, principalmente por falta de aval judicial e da Câmara de Vereadores.

A solução, então, encaminhou-se em outra direção. Em setembro de 2018, foi homologado judicialmente o acordo entre a Prefeitura de São Paulo, o MPE-SP e as incorporadoras. O principal ponto nele tratado, e que levou à conclusão das negociações, foi a denominada Transferência de Direito de Construir (TDC), um título de potencial construtivo a ser concedido como contrapartida. 
Essa ferramenta, prevista no Plano Diretor de 2014, consiste em um certificado cedido pelo poder público, que autoriza seu detentor a realizar empreendimento acima dos limites permitidos em determinadas áreas, e sem que lhe sejam impostos quaisquer ônus (SECRETARIA ESPECIAL DE COMUNICAÇÃO, 2018).

Segundo o TDC relativo ao Parque Augusta, como contrapartida pelo terreno do parque, as empresas receberam da prefeitura municipal a permissão para construir até $3.322 \mathrm{~m}^{2}$ acima do permitido em outros empreendimentos, sem pagar nada aos cofres públicos. Esse potencial construtivo, se fosse ser implementado na região do parque sem o TDC, renderia $R \$ 18,3$ milhões à administração pública. Ademais, o acordo ainda previu o pagamento de $R \$ 10$ milhões a título de indenização pelas construtoras em decorrência da ação civil pública contrária ao fechamento dos portões do parque, com o consequente encerramento do processo. Esse valor seria destinado, pela prefeitura, a uma série de finalidades:

\begin{abstract}
O termo definiu que as empresas proprietárias da área irão executar obras e pagar à municipalidade a quantia de $R \$ 10$ milhões, sendo: $R \$ 6,25$ milhões à implantação do Parque Augusta, incluindo o restauro dos bens tombados e construção do Boulevard da Rua Gravataí; $R \$ 2$ milhões para manutenção por dois anos do Parque Augusta incluindo as áreas verdes, edificações e zeladoria e $R \$ 1,6$ milhão para obras da Secretaria Municipal de Assistência e Desenvolvimento Social - SMADS (ILPI Canindé, CCInter Tucuruvi) e melhorias em escolas municipais e outros equipamentos públicos, a critério e conveniência da Administração (SECRETARIA ESPECIAL DE COMUNICAÇÃO, 2018).
\end{abstract}

Conforme nos mostra Maróstica, Cortese e Nascimento (2018), quatro propostas de projetos foram encaminhadas para a Secretaria do Verde e do Meio Ambiente (SVMA), e a partir das quais foram entregues projetos por parte das seguintes entidades ou indivíduos: Movimento Parque Augusta; arquitetos Arnaldo de Melo, Marjorie Romano Modesto e Daniela Bertuol (Sociedade dos Amigos e Moradores do Cerqueira César SAMORCC); escritório METRO Arquitetos; e Thiago Cesário Gomes.

O Estudo Preliminar aprovado pela SVMA buscou referência nos programas e equipamentos sugeridos pelos demais projetos apresentados pela sociedade, integrando as propostas em uma margem de $81 \%$ (MARÓSTICA; CORTESE; NASCIMENTO, 2018). Observa-se abaixo, no quadro esquematizado com cinco grupos de vetores (acesso, segurança, serviços administrativos, público e preservação) presentes no Estudo Preliminar, quais os pontos de cada proposta inicial (MARÓSTICA; CORTESE; NASCIMENTO, 2018). 


\begin{tabular}{|c|c|c|c|c|c|c|}
\hline Programas Equipamentos & $\begin{array}{c}\text { Movimento Parque } \\
\text { Augusta }\end{array}$ & SAMORCC & Metro & TFG & Síntese & SVMA \\
\hline Acessibilidade & Não & Não & Não & Não & Não & Sim \\
\hline Calçadas & Sim & Sim & Sim & Sim & Sim & Sim \\
\hline $\begin{array}{l}\text { Estacionamento para idosos e } \\
\text { pessoas com deficiêcia }\end{array}$ & Não & Não & Não & Não & Não & Sim \\
\hline $\begin{array}{c}\text { Portões para pedestres e } \\
\text { veículos }\end{array}$ & Sim & Não & Não & Não & Não & Sim \\
\hline Gradil & Não & Não & Não & Sim & Sim & Sim \\
\hline Guarita & Sim & Sim & Não & Não & Sim & Sim \\
\hline Administração & Sim & Sim & Não & Sim & Sim & Sim \\
\hline Área para manejo & Sim & Sim & Não & Não & Não & Sim \\
\hline $\begin{array}{l}\text { Refeitório e copa para os } \\
\text { funcionários }\end{array}$ & Não & Não & Não & Não & Sim & Sim \\
\hline Vestiários para funcionários & Não & Não & Não & Não & Sim & Sim \\
\hline Área para fogueira & Não & Não & Não & Não & Sim & Não \\
\hline Arquibancada & Não & Não & Sim & Sim & Sim & Sim \\
\hline Bancos & Não & Não & Não & Sim & Não & Sim \\
\hline Bebedouros & Sim & Sim & Não & Não & Não & Sim \\
\hline Cachorródromo & Sim & Sim & Não & Não & Sim & Sim \\
\hline Clareira com presença de água & Não & Não & Não & Não & Sim & Não \\
\hline Clareira & Sim & Não & Sim & Não & Sim & Sim \\
\hline Cascata & Não & Não & Não & Não & Sim & Não \\
\hline Deck (de madeira) & Não & Não & Não & Não & Não & Sim \\
\hline $\begin{array}{c}\text { Equipamentos de ginástica e } \\
\text { alongamento }\end{array}$ & Não & Sim & Não & Não & Não & Sim \\
\hline Espaço multiuso & Sim & Sim & Sim & Não & Sim & Sim \\
\hline Horta Comunitária & Sim & Sim & Sim & Não & Sim & Não \\
\hline Lago & Sim & Sim & Não & Sim & Sim & Não \\
\hline Lanchonetes & Não & Não & Sim & Não & Sim & Não \\
\hline Lixeiras & Não & Não & Não & Não & Não & Sim \\
\hline Pista de caminhada & Sim & Sim & Não & Sim & Sim & Sim \\
\hline Playground & Sim & Sim & Sim & Não & Sim & Sim \\
\hline Redário & Não & Não & Não & Não & Sim & Sim \\
\hline Sanitários & Sim & Sim & Sim & Sim & Sim & Sim \\
\hline Área gramada & Sim & Sim & Sim & Sim & Sim & Sim \\
\hline Bosque & Sim & Sim & Sim & Sim & Sim & Sim \\
\hline $\begin{array}{c}\text { Construções } \\
\text { históricas/tombadas }\end{array}$ & Sim & Sim & Sim & Sim & Sim & Sim \\
\hline
\end{tabular}

Quadro 2: Comparativo entre os cinco projetos desenvolvidos para o Parque Augusta. Fonte: Elaborado pelos autores, com base nos dados de Maróstica et al. (2018, p.11). 
Conforme Sayuri (2019), destacam-se três pontos no desenho do Estudo Preliminar: as áreas tombadas; as novas construções; e as trilhas. As áreas tombadas serão restauradas e a antiga portaria do Colégio Des Oiseaux, patrimônio histórico, será uma das entradas do Parque Augusta e um ponto de informações turísticas, enquanto a área do colégio será transformada em um espaço multiuso para receber atividades culturais. As novas construções, ainda de acordo com Sayuri (2019), dividiram-se entre um espaço para a prática de slackline (com $1.743 \mathrm{~m}^{2}$ ), uma arquibancada e um deck de madeira elevado de $440 \mathrm{~m}$, tudo situado na futura entrada do parque entre as ruas Augusta e Caio Prado. Ademais, será construído um redário ao lado do bosque, cuja área verde não deverá sofrer intervenções além de reparos e revitalizações pontuais.

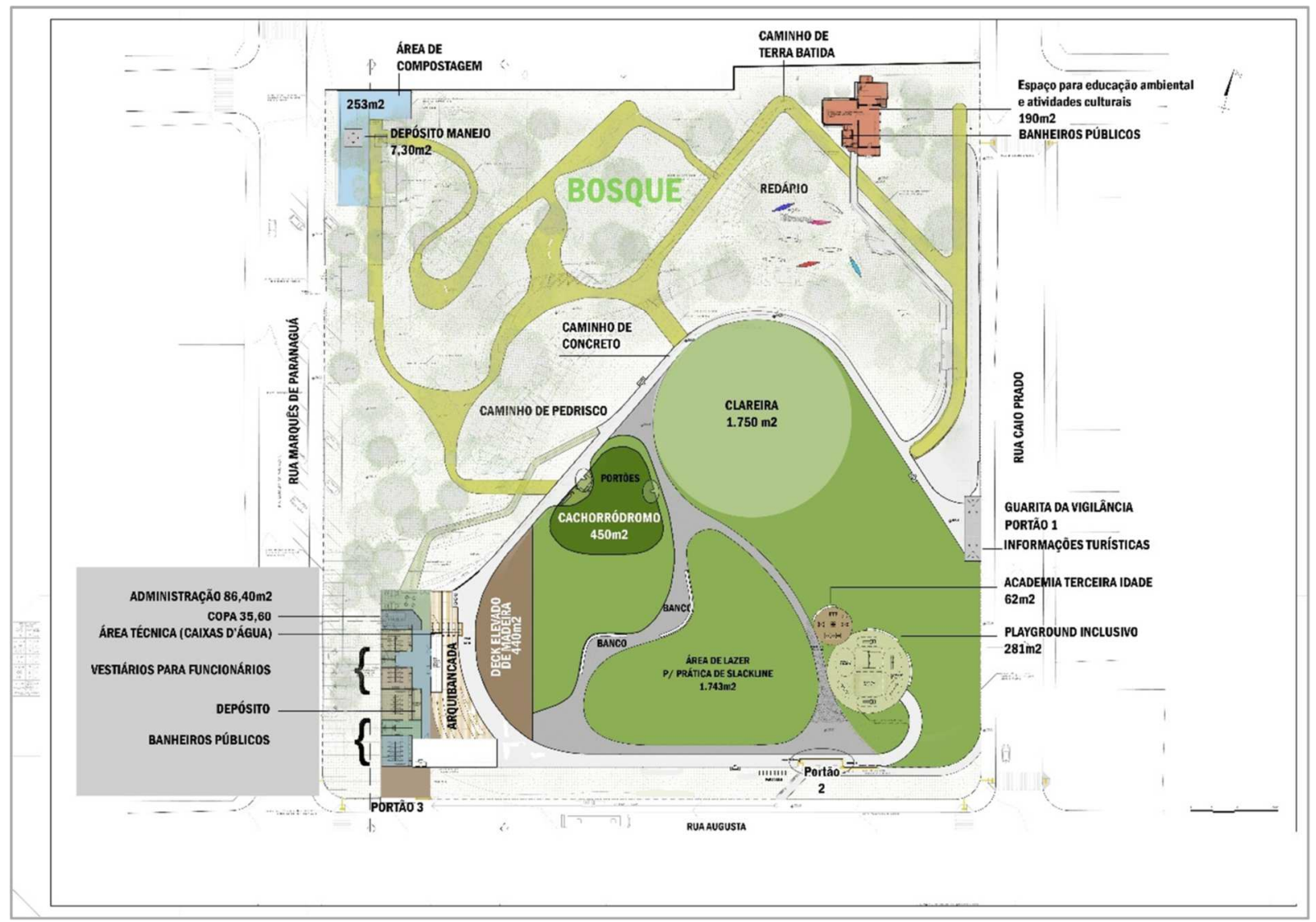

Figura 1: Projeto Final. Fonte: Bruno dos Santos Andrade (SECRETARIA ESPECIAL DE COMUNICAÇÃO, 2019).

Mais adiante, conforme o portal da Prefeitura de São Paulo (2019), no dia 06 de abril de 2019, foi assinada pelo então prefeito, Bruno Covas, a escritura de recebimento por doação do terreno do Parque Augusta à Prefeitura da cidade de São Paulo. Após a formalização do documento, a empresa doadora ficou responsável pela contratação do Projeto Executivo, obrigando-a a seguir o Estudo Preliminar, e dar início imediato às obras.

Por fim, em matéria publicada no jornal o Estado de São Paulo, no dia 11 de setembro de 2021, informa-se que as obras estão com as suas conclusões previstas para o dia 
25 de setembro de 2021e com a inauguração prevista para o mês de outubro do mesmo ano. Outro fato apontado pela autora é a existência do Projeto de Lei (PL 299/21), aprovado por maioria na Câmara Municipal em 25 de agosto de 2021, que está para ser sancionado até dia 17 de setembro, do atual prefeito da capital Ricardo Nunes. O principal ponto abordado no PL é a alteração do nome do parque para o "Parque Augusta - Prefeito Bruno Covas", em homenagem ao ex-prefeito da cidade de São Paulo Bruno Covas, que faleceu durante o seu segundo mandato em 16 de maio de 2021.

\section{CONSIDERAÇõES FINAIS}

A cidade deve ser planejada para que as pessoas ocupem os seus espaços públicos. Cada vez mais essa frase se demonstra carregada de sentindo e revela a sua importância para a qualidade e melhoria de vida no meio urbano. Em um momento em que a densidade urbana aumenta vertiginosamente, com projeções ainda mais alarmantes para os próximos anos, o planejamento urbano deve colocar primordialmente a dimensão humana no cerne das suas ideias e buscar a incorporação destes valores e premissas. Nesta mesma direção, os parques urbanos surgem como uma resposta - tanto para a efetivação da necessidade da apropriação dos espaços públicos por parte dos citadinos, como um refúgio, repleto de elementos naturais - e como um meio de enfrentamento das mazelas impostas pela urbanização - pautada exclusivamente no mercado imobiliário - e, por conseguinte, um alento para a melhoria da qualidade de vida dos cidadãos.

A inauguração do parque, prevista para outubro deste ano, é almejada com grande expectativa pelos diversos atores envolvidos na disputa da cidade, em especial, no caso dos espaços públicos, livres e abertos. Trata-se de um interessante processo que revela a condição de diálogo presente na concepção, debate e implementação dos projetos urbanos, projetos complexos que não se dissociam, na acepção lefevriana do termo, da ação social em busca da materailziaçao do rol dos direitos à cidade.

No entanto, este trabalho demonstrou de forma prática que a disputa pelos espaços públicos conta com forças contrárias, em especial, no centro da cidade de São Paulo. Ademais, para que a balança pese favoravelmente em direção ao interesse público, a participação da sociedade civil é fundamental para que as suas reivindicações sejam atendidas.

Nesse sentido, o caso do Parque Augusta é emblemático, pois, apesar de contar com normas jurídicas adeptas ao interesse público do espaço desde o século passado, a lógica mercadológica tentou prevalecer de diversas formas. Somente por meio de pressão social e intervenções jurídicas (oriundas de protestos civis) foi possível a concretização de um projeto da Prefeitura de São Paulo para a criação do parque e futuramente para usufruto de uma grande área verde no centro da cidade por todos os indivíduos e ocupação deste novo espaço urbano. 


\section{REFERÊNCIAS}

ABASCAL, E. S.; BILBAO, C. A. I. Cidadania e discricionariedade da administração pública municipal na operação urbana Água Espraiada São Paulo. Arquitextos, São Paulo, 2015. Disponível em: https://vitruvius.com.br/revistas/read/arquitextos/ 16.186/5842. Acesso em: 13 mar. 2021.

ABASCAL, E. S.; BILBAO, C. A. A emergência do Direito: ponderação no Projeto Urbano para o Parque Augusta, São Paulo. Revista de direito da Cidade, Rio de Janeiro, v. 12, n. 4, 2020. Disponível em: https://www.e-publicacoes.uerj.br/index.php/rdc/ article/view/43593. Acesso em: 14 mar. 2021.

A VIDA NO CENTRO. PALACETE, COLÉGIO DE FREIRAS, ESTACIONAMENTO: A HISTÓRIA DO PARQUE AUGUSTA. São Paulo, 21 dez. 2020. Disponível em: https://avidanocentro.com.br/cidades/historia-parque-augusta/. Acesso em: 14 set. 2021.

BURGOS, R. Direito à cidade: utopia possível a partir do uso e apropriação dos espaços públicos urbanos. In: XIV Coloquio Internacional de Geocrítica: Las utopías y la construcción de la sociedad del futuro, Anais [...]. Barcelona, 2 mai. 2016.

CASIMIRO, M. de V. A invenção e reinvenção do parque público paulistano: Um olhar sobre a produção municipal. 2018. Dissertação (Mestrado em Arquitetura e Urbanismo) - Universidade Presbiteriana Mackenzie, São Paulo, 2018.

CORRÊA, V. Acompanhe a história do terreno do Parque Augusta em mais de cem anos. Folha de S. Paulo, São Paulo, 16 mar. 2014. Disponível em: https://www1.folha.uol.com.br/saopaulo/2014/03/1425795-acompanhe-ahistoria-do-terreno-do-parque-augusta-em-mais-de-cem-anos.shtml. Acesso em: 12 jun. 2019

DALBEN, A. Notas sobre a cidade de São Paulo e a natureza de seus parques urbanos. Revista Urbana, Campinas - São Paulo, v. 8, n. 2, maio/ago. 2016. Disponível em: https://periodicos.sbu.unicamp.br/ojs/index.php/urbana/article/view/8643241. Acesso em: 13 ago. 2020.

GEHL, J. Cidades para pessoas. 3. ed. São Paulo: Perspectiva, 2015. ISBN 978-85-2730980-6.

GOMES, M. A. S. Parques Urbanos de Ribeirão Preto-SP: Na produção do espaço, o espetáculo da natureza. 2009. Tese (Doutorado em Ciências, Análise Ambiental e Dinâmica Territorial) - Universidade Estadual de Campinas, Campinas, 2009.

HARVEY, D. Cidades rebeldes: do direito à cidade à Revolução Urbana. São Paulo: Ed. Martins Fontes, 2014.

HENRIQUE, W. O direito à natureza na cidade. Salvador: Edufba, 2009. 186 p. ISBN 97885-232-0615-4. 
HORI, P. Práticas Urbanas Transformadoras: o ativismo urbano na disputa por espaços públicos na cidade de São Paulo. 2018. Dissertação (Mestrado - Arquitetura e Urbanismo) - Universidade de São Paulo, São Paulo, 2018.

JÚNIOR, S.; GUIMARÃES, A. P. M. Dialética do Parque Augusta. Periódico Técnico e Científico Cidades Verdes, São Paulo, v. 3, n. 5, p. 56-73, 2015. Disponível em: https://publicacoes.amigosdanatureza.org.br/index.php/cidades_verdes/article/v iew/954/0. Acesso em: 2 jul. 2019.

LEFEBVRE, H. O Direito à Cidade. São Paulo: Nebli, 2016. ISBN 978-85-69098-15-7.

MACHADO, L. Construtoras recusam nova proposta da Prefeitura pelo Parque Augusta. São Paulo, G1, 22 ago. 2016a. Disponível em: http://g1.globo.com/sao-paulo/ noticia/2016/08/construtoras-recusam-proposta-da-prefeitura-pelo-parqueaugusta.html Acesso em: 1 jul. 2019.

MACHADO, L. Bancos devolvem US\$ 25 milhões a SP por movimentações de Maluf. G1, São Paulo, 3 ago. 2016b. Disponível em: http://g1.globo.com/sao-paulo/noticia/ 2016/08/bancos-devolvem-us-25-milhoes-sp-por-movimentacoes-de-maluf. html. Acesso em: 3 jul. 2019.

MACHADO, L.; SANTIAGO, T. Parque Augusta será implementado por construtoras, diz secretário. G1, São Paulo, 5 jun. 2017. Disponível em: https://g1.globo.com/saopaulo/noticia/parque-augusta-sera-implemntado-por-construtoras-dizsecretario.ghtml Acesso em: 26 jun. 2019.

MARÓSTICA, J. R.; CORTESE, T, T. P.; NASCIMENTO, A. P. B. do. Implantação do Parque Augusta: critérios para unificar as diferentes demandas solicitadas pela população. In: SINGEP - Simpósio Internacional de Gestão de Projetos, Inovação e Sustentabilidade, VII. Anais [...]. São Paulo: [s. n.], 2018.

MELLO, D. Polícia de São Paulo cumpre mandado de reintegração de posse no Parque Augusta. Agência Brasil, São Paulo, 4 mar. 2015. Disponível em: http://agencia brasil.ebc.com.br/geral/noticia/2015-03/policia-cumpre-mandato-dereintegracao-de-posse-no-parque-augusta. Acesso em: 7 jul. 2019.

MENGUE, P. Parque Augusta deve ser aberto em outubro. Estadão Digital, São Paulo, 7 set. 2021. Disponível em: https://digital.estadao.com.br/article/2815093443075 44?fbclid=IwAR1J9n2xORnwmedU0_pUfhRO7Nq90 crlaFCO49wyb5JxAcNnzPnxZYbNU8. Acesso em: 21 set. 2021.

MITCHELL, D. The End of Public Space? People's Park, Definitions of the Public, and Democracy. Annals of the Association of American Geographers, Colorado - EUA, v. 85, n. 1, p. 108-133, 01 jun. 1995. Disponível em: https://www.tandfonline. com/doi/abs/10.1111/j.1467-8306.1995.tb01797.xa. Acesso em: 12 fev. 2021.

ORGANIZAÇÃO DAS NAÇÕES UNIDAS. FAO framework for the Urban Food Agenda: Leveraging sub-national and local government action to ensure sustainable food systems and improved nutrition 2019. Disponível: http://www.fao.org/3/ ca3151en/CA3151EN.pdf. Acesso em: 02 mai. 2020. 
ROLNIK, R. Guerra dos lugares: A colonização da terra e da moradia na era das finanças. São Paulo: Boitempo Editorial, 2019.

SAKATA, F. G. Parques urbanos no Brasil 2000 a 2017. 2018. Tese (Doutorado em Arquitetura e Urbanismo) - Universidade de São Paulo, São Paulo, 2018.

SALDANHA, N. O jardim e a praça. São Paulo: Yendis, 2005.

SAYURI, J. Como é o novo projeto do parque Augusta em São Paulo. Nexo Jornal, São Paulo, 26 ago. 2019. Disponível em: https://nexojornal.com.br/expresso/2019/ 04/06/Como-é-o-novo-projeto-do-parque-Augusta-em-São-Paulo. Acesso em: 26 ago. 2019.

SECRETARIA MUNICIPAL DO VERDE E DO MEIO AMBIENTE. O Parque Augusta se tornará realidade. Portal da Prefeitura da Cidade de São Paulo, São Paulo, 4 ago. 2017. Disponível em: https://www.prefeitura.sp.gov.br/cidade/secretarias/ meio_ambiente/noticias/?p=238805. Acesso em: $10 \mathrm{dez} .2021$.

SECRETARIA ESPECIAL DE COMUNICAÇÃO. Justiça homologa acordo para criação do Parque Augusta. Portal da Prefeitura da Cidade de São Paulo, São Paulo, 21 set. 2018. Disponível em: http://www.capital.sp.gov.br/noticia/justica-homologaacordo-para-criacao-do-parque-augusta. Acesso em: 7 jul. 2019.

SECRETARIA ESPECIAL DE COMUNICAÇÃO. Prefeitura de São Paulo assina escritura do terreno do futuro Parque Augusta. Portal da Prefeitura da Cidade de São Paulo, São Paulo, 6 abr. 2019. Disponível em: http://www.capital.sp.gov.br/noticia/ prefeitura-de-sao-paulo-assina-escritura-do-terreno-do-futuro-parque-augusta. Acesso em: 13 set. 2021.

VEIGA, E. Cronologia do terreno do Parque Augusta (1902-2015). Estadão, São Paulo, 3 mar. 2015. Disponível em: https://sao-paulo.estadao.com.br/blogs/edisonveiga/cronologia-do-terreno-do-parque-augusta-1902-2015/. Acesso em: 12 jun. 2019. 